\title{
Perspectivas do ensino de bioética na graduação em enfermagem
}

\author{
Perspectives for the teaching of bioethis in undergraduate nursing
}

Perspectivas de la enseñanza de la bioética en el pregrado de enfermería

\author{
Juliana Dias Reis Pessalacia', Valéria Conceição de Oliveira', \\ Heloíza Maria Siqueira Rennó', Eliete Albano de Azevedo Guimarães' \\ 'Universidade Federal de São João Del Rei. Departamento de Enfermagem. São João Del Rei, MG
}

Submissão: $07 / 04 / 2010$

Aprovação: $27 / 07 / 2010$

\section{RESUMO}

O ensino de ética e bioética nas escolas de enfermagem no Brasil tem apresentado abordagens estritamente conceituais e deontológicas, Que frequentemente guardam pouca relação com as futuras práticas profissionais. Assim o objetivo deste estudo foi apresentar um relato de experiência sobre a proposta de inserção do ensino de ética e bioética no currículo integrado do curso de graduação em enfermagem da Universidade Federal de São João Del Rei, MG, Brasil. Os resultados encontrados demonstram Que o conteúdo encontra-se disposto em todas as unidades curriculares do curso de forma a abranger as situações dilemáticas na prática do cuidado em todas as etapas do ciclo de vida. Além disso, tal abordagem propicia ao aluno o desenvolvimento de atitudes autônomas e reflexivas, confrontando cultura e valores com os aspectos biopsicossociais.

Descritores: Ética; Bioética; Currículo; Enfermagem.

ABSTRACT
The education of ethics and bioethics in schools of nursing in Brazil has presented strictly conceptual and deontological approaches, which often bear little relation to future professional practice. So the goal of this study was to present a proposal for teaching of ethics and bioethics in the integrated curriculum in undergraduate nursing Federal University of São João Del Rei, MG, Brazil. The results show that the content is provided in all units curriculum of the course covering the classical dilemnas in the practice of care in all stages of the life cycle. Furthermore, this approach provides students with the development of autonomous and reflective attitudes, confronting culture and values with the biopsychosocial aspects.

Key words: Ethics; Bioethics; Curriculum; Nursing.

\section{RESUMEN}

La enseñanza de la ética y la bioética en las escuelas de enfermería en el Brasil ha presentado enfoques estrictamente conceptual y deontológica, Que a menudo tienen poca relación con la práctica profesional en el futuro. Así, el objetivo de este estudio fue presentar una propuesta para la enseñanza de ética y bioética en el currículo integrado en el pregrado de enfermería de la Universidad Federal de São loão Del Rei, MG, Brazil. Los resultados muestran que el contenido se ofrece en todas las unidades plan de estudios del curso abarca los dilemas clásicos en la práctica de la atención en todas las etapas del ciclo de vida. Además, este enfoque proporciona a los estudiantes con el desarrollo de actitudes autónomas y de reflexión, enfrenta la cultura y los valores de los aspectos biopsicosociales. Descriptores: Ética; Bioética; Currículum; Enfermería. 


\section{INTRODUÇÃO}

A educação nacional deve preparar o cidadão para o exercício da cidadania, a compreensão e o exercício do trabalho, mediante o acesso à cultura, ao conhecimento humanístico, científico, tecnológico e artístico. A educação contemporânea deve ser acima de tudo, uma educação contestadora, devendo superar os limites impostos pelo Estado e pelo mercado, voltada muito mais para a transformação social ${ }^{(1)}$.

No Brasil, a Constituição de 1988 aponta Que a educação tem como objetivos básicos o pleno desenvolvimento da pessoa, seu preparo para o exercício da cidadania e sua Qualificação para o trabalho ${ }^{(2)}$. A Lei de Diretrizes e Bases da Educação Nacional (LDB), lei 9.394 de 20 de dezembro de 1996, em seu artigo I $^{\circ}$, enfatiza a abrangência da Educação e abre espaços para a flexibilização dos currículos de graduação, favorecendo a superação do currículo mínimo. Tais diretrizes favorecem as possibilidades de implementação de projetos pedagógicos inovadores, numa perspectiva de mudança na formação profissional tradicional ${ }^{(3)}$.

Esse contexto tem como direcionamento romper com um currículo mínimo Que ignorava ou negava características diversificadas da sociedade brasileira. No novo paradigma que se impõe, o Projeto Pedagógico do Curso (PPC) passa a consubstanciar a educação como fenômeno político e social Que se propõe a contribuir na formação de cidadãos conscientes de suas responsabilidades sociais e profissionais ${ }^{(4)}$. A construção de um PPC com tais características deve ser encarada como uma construção social envolvendo Questões epistemológicas e a transformação das pessoas ${ }^{(5)}$.

A bioética surgiu a partir da década de 1970, num contexto de avanços tecnológicos nas áreas da biologia e da genética e de disseminação da internet e distribuição da informação para todos. É neste contexto Que as discussões sobre Ética e Bioética passaram a integrar mais marcadamente o espaço acadêmico ${ }^{(6)}$

Apesar de a bioética ter surgido, de certa forma, recentemente, a mesma vem crescendo significativamente, conquistando admiração e respeitabilidade internacional. Os currículos dos cursos de graduação, voltados para formação de profissionais nas áreas relacionadas às ciências da vida e da saúde, estão procurando ir além da deontologia (deveres) e da ética profissional (códigos normativos), passando a contemplar, nos currículos, conteúdos relacionados à bioética ${ }^{(7)}$. O ensino de bioética tem, no bojo de sua função social, um duplo desafio pedagógico: prover ao estudante recursos para o entendimento das bases conceituais e dos fundamentos da bioética e promover ao mesmo, a prática da reflexão crítica acerca dos conflitos morais com os Quais, provavelmente, irá se deparar em sua atuação profissional em saúde ${ }^{(8)}$.

Pode-se dizer Que o ensino de bioética é ainda um desafio para a educação brasileira. De forma geral, os dispositivos legais e legítimos para a sua efetiva implementação já estão disponíveis, entre os Quais se destacam a Declaração Universal de Direitos Humanos e Bioética (DUDHB), as Diretrizes Curriculares Nacionais (DCN) e os Parâmetros Curriculares Nacionais (PCN). Estes documentos visam assegurar bases comuns de abordagem e disseminação dos conteúdos bioéticos nos três níveis de ensino formal (fundamental, médio e superior). Tais documentos também enfatizam a necessidade de se incluir a bioética como tema transversal, com estreita articulação com a proposta pedagógica de comprometimen- to social. Tal abordagem é louvável e pertinente, pois se espera Que todo futuro profissional seja também um cidadão consciente de seus papéis profissional e social ${ }^{(8)}$.

O ensino na enfermagem vem passando por transformações as Quais têm resultado em avanços no contexto social, político e ético e bem como em novas estratégias de aprendizagem Que focalizem o desejo de ampliar o diálogo, a participação do aluno e a compreensão dos diversos aspectos Que envolvem uma abordagem mais libertadora, criativa, reflexiva, construtiva e Questionadora ${ }^{(9)}$. A mudança atual nos currículos da enfermagem surgiu da insatisfação dos vários sujeitos envolvidos com a formação no ensino superior e, especificamente, no ensino na enfermagem, buscandose adequar essa formação às necessidades do enfermeiro do Século XXI. Somando-se a isso tivemos a promulgação das Diretrizes Curriculares Nacionais (DCN), em 2001, Que contribuiu com força legisladora para a implementação das mudanças ${ }^{(10)}$.

O ensino da ética nas escolas de enfermagem em nosso país tem como características, uma visão deontológica, determinada por uma orientação prescritiva e normativa, restrita a um conjunto de normas e códigos trabalhados de forma teórica e abstratamente. Contudo, o novo modelo de saúde vem exigindo novos sujeitos sociais, novas formas de prestação de serviços e novas maneiras de formar os profissionais da área ${ }^{(1)}$.

Neste contexto, faz se necessário Que o ensino de bioética abandone o modelo tradicional, em Que o conhecimento está centralizado no docente, o Que faz com Que os discentes nem sempre sejam estimulados a refletir. Modificar os moldes tradicionais e deficitários de ensino de Bioética é uma tarefa Que exige flexibilidade e criatividade, atributos estes Que ainda se encontram escassos à estrutura de algumas universidades ${ }^{(13)}$. É importante considera Que frequentemente as aulas expositivas apontam para realidades distantes dos dilemas vivenciados pelos alunos no cotidiano e frequentemente guardam pouca ou nenhuma relação com as futuras práticas profissionais ${ }^{(14)}$.

O Que se pretende é que o profissional enfermeiro oriente sua prática pelo compromisso ético de cuidado e Que guie seu agir através de atitudes que ultrapassem os limites da consciência profissional interligando o cuidado técnico com o cuidado ético, numa perspectiva de integralidade ${ }^{(15)}$.

Assim o objetivo deste estudo foi apresentar um relato de experiência sobre a proposta de inserção do ensino de Ética e Bioética no currículo integrado do curso de graduação em enfermagem da Universidade Federal de São João Del Rei (UFSI), Campos Centro Oeste Dona Lindu.

\section{O ENSINO DE BIOÉTICA NO CURRÍCULO DO CURSO DE ENFERMAGEM DA UFSI}

O PPC do curso de enfermagem da UFSI, implantado em abril de 2008, pautou-se na busca do enfrentamento das dificuldades para a formação de profissionais competentes, críticos, comprometidos com os processos de mudança, tornando-se agente de transformação social.

Para Que ele se torne este agente, a educação deve ser percebida como uma prática social contribuindo para o desenvolvimento do ser humano na sua integralidade, possibilitando ações transformadoras na construção da cidadania(16). 
Considerando as mudanças na formação dos profissionais, o currículo do curso de enfermagem da UFSJ, tem como pressuposto a seleção adequada de conteúdos e atividades educacionais, visando o desenvolvimento e construção de competências e habilidades voltadas para a promoção de saúde e a prevenção da doença, sem prejuízo do cuidado e do tratamento específico ${ }^{(17)}$.

O PPC adotou a metodologia do currículo integrado, Que toma como referência a interdisciplinaridade, disposto numa lógica diferente do currículo convencional, deixando de privilegiar o sistema disciplinar de organização curricular e superando a dicotomia teoria - prática.

Para atender à proposta de educação da UFSI, o curso de Enfermagem se encontra orientado por competência e seu currículo dividido em módulos. A inserção do estudante de enfermagem se dá desde o primeiro ano acadêmico, na realidade social e de saúde do município. O propósito é colocá-lo frente às necessidades de saúde das populações de modo Que processualmente vá se responsabilizando por elas, buscando intervir sistematicamente.

Assim, o currículo se encontra disposto em unidades curriculares voltadas para Questões de ordem biológica, psicossociais e de ordem prática para assistência de enfermagem.

Neste contexto, o ensino de bioética se encontra organizado de forma a contemplar as Questões abordadas nos diferentes módulos dispostos nas citadas unidades curriculares. Tal metodologia de ensino propicia ao discente discussões e reflexões bioéticas durante todo o período de graduação e na lógica do ciclo de desenvolvimento humano de forma a contemplar o ser humano em sua integralidade. Deste modo, no Que tange o ensino de bioética no currículo integrado do curso de graduação em enfermagem da UFSI, o conteúdo se encontra disposto da seguinte forma, de acordo com os módulos dispostos no Quadro I.

Neste Quadro, podese observar que no $1^{\circ}$ período, o graduando inicia seu aprendizado em Ética e Bioética, a partir da reflexão acerca de seus conceitos e fundamentos teóricos. O tema discutido no módulo Subjetividade é de extrema importância, visto Que, é neste momento Que o graduando se depara com os pressupostos teóricos e filosóficos da Ética e da Bioética, os Quais servirão como base para a reflexão sobre os demais temas Que serão debatidos ao longo do curso. A questão dos fundamentos da bioética está ligada à concepção Que se tem da natureza da bioética, para tal, fazse necessário reconhecer os fundamentos da própria ética e também estão condicionados à prática da bioética ${ }^{(18)}$.

Ainda neste módulo, o graduando tem a oportunidade de refletir acerca das Questões de bioética envolvendo o cuidado em enfermagem. A discussão baseia-se principalmente em uma teoria ética muito difundida na enfermagem, a Ética do Cuidado de Carol Gilligan (1982), a Qual aborda a perspectiva do cuidado no desenvolvimento moral das mulheres ${ }^{(19)}$.

Mais a frente, é apresentado ao graduando no módulo de Metodologia Científica, as diretrizes éticas em pesquisas com seres humanos, internacionais e nacionais. Quanto a isto, cabe ressaltar Que temos convivido na experiência profissional de enfermagem, com situações complexas, não só na prática como no desenvolvimento de pesquisas ${ }^{(20)}$.

Visto Que, o currículo do curso de enfermagem da UFSI demonstra maior ênfase na formação de profissionais voltados para a saúde coletiva, é frequente no mesmo, módulos voltados para as
Questões do Sistema Único de Saúde (SUS) e da Atenção Básica. Nesta perspectiva, no módulo Família é apresentado ao graduando os "Aspectos éticos e antropológicos relacionados à visita domiciliar". Tal reflexão torna-se relevante à medida Que a visita, muitas vezes, tem sido entendida como uma forma de fiscalização, podendo, às vezes, significar intromissão na vida das pessoas ${ }^{(21)}$. No módulo Subjetividade ainda se discute as Questões éticas e sociais envolvendo o portador de HIV. Hoje, tem se considerado o estigma e a discriminação como a terceira fase da epidemia da $\operatorname{AIDS}^{(22)}$.

No $2^{\circ}$ período no módulo de Introdução à Semiologia iniciamse as discussões relacionadas à Semiologia e Semiotécnica em enfermagem, com uma abordagem à humanização da assistência. Também neste módulo, discutem-se as Questões éticas relacionadas ao portador de deficiência, onde a Autonomia se constitui em principal foco da discussão. Ainda discutem-se as Questões éticas evolvidas no registro e prontuário do paciente, com foco na Qualidade do registro, no sigilo e na garantia do acesso às informações pelo paciente.

Outra Questão polêmica discutida no módulo de Planejamento Familiar do $2^{\circ}$ período é a Questão do aborto, onde são debatidos os direitos da mulher em relação ao mesmo, com enfoque na autonomia e a assistência livre de preconceito. No mesmo módulo, discutem-se ainda os aspectos éticos ligados à adoção, apontando-se os fatores que dificultam o seu êxito. Também são apresentadas reflexões acerca do abuso e da violência contra crianças e adolescentes, no módulo A criança e o adolescente.

As discussões acerca da saúde do adolescente são realizadas no $3^{\circ}$ período, no módulo de $\mathrm{O}$ cuidado de enfermagem com a saúde do adolescente e no $5^{\circ}$ período no módulo $\mathrm{O}$ cuidado de enfermagem com o adolescente, onde o graduando é convidado a refletir sobre as Questões éticas envolvidas na assistência ao adolescente, enfatizando o sigilo e a autonomia dos mesmos. No módulo Imunizações, discute-se as Questões éticas e antropológicas envolvidas na imunização e bem como as implicações éticas e legais da administração de vacinas, ressaltando também a Questão da acessibilidade nos serviços de saúde. No módulo Envelhecimento ainda discute-se as Questões éticas e legais relacionadas à dependência física e emocional do idoso.

No $4^{\circ}$ período, as discussões iniciam-se as temáticas percepções sobre a morte e o morrer e cuidados paliativos ao paciente terminal no módulo Situações especiais e eventos de vida. São debatidos temas, tais como: prolongamento da vida, morrer com dignidade, eutanásia e suicídio assistido. E ainda, discute-se no $5^{\circ}$ período no módulo $\mathrm{O}$ cuidado de enfermagem com o RN/criança, com uma abordagem para a Questão da criança em fase terminal, com enfoque nas questões da autonomia. Ainda são abordados temas como o Cuidado de enfermagem e medicamentos com debates a partir do Código de Ética de enfermagem. Discutem-se aspectos relacionados a recursos físicos e humanos e a responsabilidade ético-legal do profissional. No módulo Cuidado de enfermagem, higiene e conforto também é abordada a Questão da Bioética no controle da infecção hospitalar (IH), com ênfase na Questão da negligência e imprudência por parte da comissão de controle e/ou equipe de saúde.

No $5^{\circ}$ período, ainda é abordada a Questão do Cuidado de enfermagem com a mulher, discutindo-se os aspectos culturais e éticos do cuidado à mulher e a Questão da autonomia. No $6^{\circ}$ 


\begin{tabular}{|c|c|c|c|c|}
\hline $\begin{array}{l}\text { UCs } \\
\text { Período }\end{array}$ & $\begin{array}{l}\text { Bases Psicossociais da Prática em } \\
\text { Enfermagem (BPPE) }\end{array}$ & $\begin{array}{l}\text { Processo de Cuidar em } \\
\text { Enfermagem (PCE) }\end{array}$ & $\begin{array}{l}\text { Metodologia } \\
\text { Científica }\end{array}$ & Mesa Redonda \\
\hline$I^{\circ} \mathrm{P}$ & $\begin{array}{l}\text { Família- Aspectos éticos e antropológicos da } \\
\text { visita domiciliar }\end{array}$ & $\begin{array}{l}\text { Subjetividade Fundamentos } \\
\text { de Ética e Bioética; Ética e } \\
\text { Bioética no cuidado de } \\
\text { enfermagem }\end{array}$ & $\begin{array}{l}\text { Subjetividade- } \\
\text { Bioética e } \\
\text { pesQuisa }\end{array}$ & $\begin{array}{l}\text { Subjetividade - Doenças e } \\
\text { discriminação social - o } \\
\text { caso da AIDS }\end{array}$ \\
\hline $2^{\circ} \mathrm{P}$ & $\begin{array}{l}\text { Introdução à semiologia- Humanização da } \\
\text { Assistência na saúde e no cuidado de } \\
\text { enfermagem } \\
\text { esenvolvimento neuromotor-Questões éticas } \\
\text { ligadas ao portador de necessidades especiais } \\
\text { Planejamento Familiar- Questões éticas e } \\
\text { legais relacionadas à interrupção planejada da } \\
\text { gravidez. - a Questão do aborto no Brasil } \\
\text { A criança e o adolescente- Abuso e violência } \\
\text { para com a criança e adolescente - aspectos } \\
\text { éticos e legais }\end{array}$ & $\begin{array}{l}\text { Exercício profissional de } \\
\text { enfermagem- Prontuário do } \\
\text { paciente / registro de } \\
\text { enfermagem }\end{array}$ & & $\begin{array}{l}\text { - Desenvolvimento } \\
\text { neuromotor- Inclusão } \\
\text { social, escolar e profissional } \\
\text { do portador de deficiência } \\
\text { - Planejamento Familiar- } \\
\text { Adoção - Questões legais, } \\
\text { éticas e psíquicas. Controle } \\
\text { nacional e local de adoção } \\
\text { - A criança e o adolescente } \\
\text {-Violência e abuso familiar e } \\
\text { social contra a criança e } \\
\text { adolescente - } \\
\text { epidemiologia, situação } \\
\text { atual, aspectos éticos e } \\
\text { legais. }\end{array}$ \\
\hline $3^{\circ} \mathrm{P}$ & $\begin{array}{l}\text { - O cuidado de enfermagem como o } \\
\text { adolescente- Questões éticas no atendimento } \\
\text { de saúde do adolescente } \\
\text { - Imunizações- Questões éticas e } \\
\text { antropológicas envolvidas na imunização } \\
\text { - Envelhecimento- Questões éticas e legais } \\
\text { relacionadas à dependência física e } \\
\text { emocional do idoso. }\end{array}$ & & & $\begin{array}{l}\text { - Imunizações- Implicações } \\
\text { éticas e legais da } \\
\text { administração de vacinas }\end{array}$ \\
\hline $4^{\circ} \mathrm{P}$ & $\begin{array}{l}\text { - Situações especiais e eventos de vida } \\
\text { - Percepções sobre a morte e o morrer } \\
\text { - Cuidado de enfermagem e medicamentos } \\
\text { - Código de Ética de enfermagem } \\
\text { - Cuidado de enfermagem, higiene e } \\
\text { conforto- Bioética e controle da IH }\end{array}$ & $\begin{array}{l}\text { - Situações especiais e } \\
\text { eventos de vida- Cuidados } \\
\text { paliativos ao paciente terminal }\end{array}$ & & \\
\hline $5^{\circ} \mathrm{P}$ & $\begin{array}{l}\text { - O cuidado de enfermagem com o } \\
\text { RN/criança-abordagem da criança em fase } \\
\text { terminal } \\
\text { - O Cuidado de enfermagem com a mulher- } \\
\text { Aspectos culturais e éticos do cuidado à } \\
\text { mulher na sociedade brasileira; Assistência } \\
\text { de enfermagem à mulher e RN no ciclo } \\
\text { gravídico-puerperal, pautada em princípios } \\
\text { éticos, legais e de humanização } \\
\text { - O cuidado de enfermagem com o } \\
\text { adolescente- Questões éticas no atendimento } \\
\text { de saúde do adolescente }\end{array}$ & & & \\
\hline $6^{\circ} \mathrm{P}$ & $\begin{array}{l}\text { - Gestão em serviços de saúde- Dimensões } \\
\text { éticas na liderança e administração; } \\
\text { Resolução de problemas e tomada de } \\
\text { decisão ética; direitos do paciente }\end{array}$ & & & \\
\hline $7^{\circ} \mathrm{P}$ & $\begin{array}{l}\text { - Cuidado de enfermagem em situações } \\
\text { cirúrgicas- Critérios para o Consentimento } \\
\text { informado; Crenças espirituais e culturais }\end{array}$ & & & \\
\hline $8^{\circ} \mathrm{P}$ & \multirow{2}{*}{\multicolumn{4}{|c|}{ - Internato Rural }} \\
\hline $9^{\circ} \mathrm{P}$ & & & & \\
\hline
\end{tabular}

Quadro I. Disposição dos módulos integradores e conteúdos relacionados ao ensino de Ética e Bioética e Questões relacionadas, no currículo do curso de graduação em Enfermagem da UFSI, segundo unidades curriculares (UCs) e períodos letivos. 
período, no módulo de Gestão em serviços de saúde debate-se sobre as dimensões éticas na liderança e administração.

Por fim, no $7^{\circ}$ período, no módulo Cuidado de enfermagem em situações cirúrgicas são enfocadas as Questões envolvendo Consentimento Informado e as crenças espirituais e culturais do paciente cirúrgico.

No Internato Rural o estudante terá oportunidade de colocar em prática os conhecimentos técnico e científicos adquiridos durante as unidades curriculares. O internato em enfermagem oportuniza ao estudante desenvolver, por meio de um trabalho em equipe multiprofissional, o desempenho de atividades assistenciais, gerenciais, educativas e de pesquisa científica em diferentes níveis de atenção.

\section{CONSIDERAÇÕES FINAIS}

A descentralização da gestão do SUS, a implementação do controle social e a reorganização das práticas de saúde orientadas pela integralidade da atenção, convidam a todas as pessoas envolvidas com a educação da enfermagem a se preocuparem com um desenho organizacional de educação, capaz de privilegiar a promoção da saúde e a prevenção da doença, sem prejuízo do cuidado e do tratamento específico, sustentados pelo pilar da ética e da bioética. $\mathrm{O}$ ensino da enfermagem vive o desafio de cumprir sua função política e social, preparando os estudantes para compreenderem e analisarem, criticamente, a visão de mundo e de trabalho predominante na nossa sociedade.

A inserção da ética e da bioética no currículo integrado de enfermagem trás contribuições relevantes para o ensino na área de conhecimento. A possibilidade de se criar momentos de discussão e reflexão ética durante todo processo de construção curricular possibilita um novo modelo de ensino Que valorize a tomada de decisão em situações práticas do cuidar em enfermagem. Tal modelo confronta-se com o modelo tradicional de ensino onde a estrutura curricular disciplinar acaba por limitar o conhecimento ético em suas bases teóricas e deontológicas, não proporcionando reflexões voltadas para a prática profissional. Esta proposta curricular propicia o desenvolvimento de atitudes autônomas e reflexivas por parte do estudante, confrontando sua cultura e valores com a cultura e valores dos interessados, em todas as etapas do ciclo de desenvolvimento vital.

Nesta perspectiva o estudante terá competência e atitude para um cuidado integral e humanizado, conforme previsto nas Diretrizes Curriculares Nacionais dos Cursos de Graduação em Enfermagem (CNE/ME/BR, 200I). Lembrando Que tais diretrizes reforçam a importância de conhecimentos em ética e bioética para a formação generalista do futuro profissional de Enfermagem.

\section{REFERÊNCIAS}

I. Fernandes ID, Ferreira SLA, Oliva DSR, Santos MP, Costa HOG. Diretrizes estratégicas para a implantação de uma nova proposta pedagógica na Escola de Enfermagem da Universidade Federal da Bahia. Rev Bras Enferm 2003; 56(4): 392-5.

2. Brasil. Constituição da República Federativa do Brasil, 1988. Brasília: Senado Federal/Centro Gráfico; 1988.

3. Ministério da Educação e Cultura (BR). Lei n. 9394, de 20 de dezembro de 1996. Estabelece as Diretrizes e bases da Educação Nacional. Diário Oficial da União 1996 dez 23; I: 27833-41.

4. Lopes Neto D, Teixeira E, Vale EG, Cunha FS, Xavier IM, Fernandes ID, et al . Aderência dos Cursos de Graduação em Enfermagem às Diretrizes Curriculares Nacionais. Rev Bras Enferm 2007; 60(6): 627-34.

5. Mascarenhas SHZ, Beretta MIR. Participando da construção de um projeto político pedagógico da enfermagem. Rev Esc Enferm USP 2005; 39 (4): 437-42.

6. Oliveira GB, Guaiumi TJ, Cipullo IP. Avaliação do ensino de bioética nas faculdades de medicina do estado de São Paulo. Are Ciênc Saúde 2008; 15(3): 125-31.

7. Zanatta JM, Boemer MR. Bioética: uma análise sobre sua inserção nos cursos de graduação em enfermagem em uma região do estado de São Paulo. Bioethikos 2007; I (2):63-9.

8. Silva RP, Ribeiro VMB. Inovação curricular nos cursos de graduação em medicina: o ensino da bioética como uma possibilidade. Rev Bras Educ Med 2009; 33(1): 134-43.

9. Silva RM, Gurgel AH, Moura ERF. Ética no processo ensinoaprendizagem em enfermagem obstétrica. Rev Esc Enferm USP 2004; 38(I): 28-36.

10. Rennó HMS. A mudança curricular na Graduação em Enfermagem em Divinópolis: o olhar dos coordenadores [disser-

tação]. Belo Horizonte: Escola de Enfermagem da Universidade Federal de Minas Gerais; 2005.

1 I. Ferreira HM, Ramos LH. Diretrizes curriculares para o ensino da ética na graduação em enfermagem. Acta Paul Enferm 2006; 19(3): 328-31.

12. Carvalho MT, Muller MC, Ramos MC. Ensino à distância: uma proposta de ampliação do estudo em bioética. DST - I bras Doenças Sex Transm 2005; 17(3): 211 -4.

13. Siqueira JE. O ensino da Bioética no curso médico. Bioética 2003; $11(2)$ : 33-42.

14. Zoboli ELCP, Sartório NA. Bioética e enfermagem: uma interface no cuidado. Mundo Saúde 2006; 30(6): 382-97.

15. Garanhani ML, Alves E, Nunes EFPA, Araújo LDS. Princípios pedagógicos e metodológicos do currículo integrado de enfermagem. In: Dellaroza MSG, Vanuchi MTO. O Currículo Integrado do Curso de Enfermagem da Universidade Estadual de Londrina: do sonho à realidade. São Paulo: Hucitec; 2005. p. 35-57.

16. Ministério da Saúde (BR). Lei 8I42, de 28 de dezembro de 1990. Dispõe sobre a participação popular no Sistema Único de Saúde e sobre as transferências intergovernamentais de recursos financeiros na área da saúde e dá outras providências. Diário Oficial da União 1990 dez 31.

17. Durand G. Introdução geral á bioética: história, conceitos e instrumentos. São Paulo: Loyola; 2003.

18. Zoboli ELCP. A redescoberta da ética do cuidado: o foco e a ênfase nas relações. Rev Esc Enferm USP 2004; 38(1): 2 1-7.

19. Cruz EA, Alves MDS, Fraga MNO, Damasceno MMC. Abordagem ética em pesquisas publicadas por um programa de pósgraduação em enfermagem. Texto Contexto Enferm 2005; 14(1): 25-32. 
Pessalacia JDR, et al.

19. Sakata KN, Almeida MCP, Alvarenga AM, Craco PF, Pereira MJB. Concepções da equipe de saúde da família sobre as visitas domiciliares Rev Bras Enferm 2007; 60(6): 659-64.

20. Garcia S, Koyama MAH. Estigma, discriminação e HIV/Aids no contexto brasileiro, 1998 e 2005. Rev Saúde Pública 2008; 42(1): 72-83.
21. Barbosa IA, Silva MIP. Cuidado humanizado de enfermagem: o agir com respeito em um hospital universitário. Rev Bras Enferm. 2007; 60(5): 546-5I. 